\title{
Modelling the impact of noctilucent cloud formation on atomic oxygen and other minor constituents of the summer mesosphere
}

\author{
B. J. Murray ${ }^{1, *}$ and J. M. C. Plane ${ }^{1}$ \\ ${ }^{1}$ School of Environmental Sciences, University of East Anglia, Norwich, UK NR4 7TJ \\ *now at: Department of Chemistry, University of British Columbia, Vancouver, British Columbia, Canada V6T 1Z1
}

Received: 7 April 2004 - Published in Atmos. Chem. Phys. Discuss.: 5 November 2004

Revised: 4 February 2005 - Accepted: 15 March 2005 - Published: 29 March 2005

\begin{abstract}
The formation, evolution and eventual sublimation of noctilucent clouds (NLC) may have a significant effect on the odd oxygen and hydrogen chemistry of the high latitude summer mesosphere. Three mechanisms are considered here: the direct uptake of atomic oxygen on the surface of the ice particles; the redistribution of water vapour, which changes the photochemical source of odd hydrogen species; and the direct photolysis of the ice particles themselves to produce odd hydrogen species in the gas phase. A 1-D photochemical model is employed to investigate the potential importance of these mechanisms. This shows, using the recently measured uptake coefficients of $\mathrm{O}$ on ice, that the heterogeneous removal of $\mathrm{O}$ on the surface of the cloud particles is too slow by at least a factor of $5 \times 10^{3}$ to compete with gas-phase $\mathrm{O}$ chemistry. The second and third mechanisms involve the solar Lyman- $\alpha$ photolysis of $\mathrm{H}_{2} \mathrm{O}$ in the gas and solid phase, respectively. During twilight, Lyman- $\alpha$ radiation is severely attenuated and these mechanisms are insignificant. In contrast, when the upper mesosphere is fully illuminated there is a dramatic impact on the $\mathrm{O}$ profile, with depletion of $\mathrm{O}$ at the base of the cloud layer of close to an order of magnitude. A correspondingly large depletion in $\mathrm{O}_{3}$ is also predicted, while $\mathrm{H}, \mathrm{OH}, \mathrm{HO}_{2}$ and $\mathrm{H}_{2} \mathrm{O}_{2}$ are found to be enhanced by factors of 3-5. In fact, rocket-borne mass spectrometer measurements during summer have revealed local $\mathrm{H}_{2} \mathrm{O}_{2}$ enhancements in the region of the clouds. Rocketborne measurements of atomic $\mathrm{O}$ and $\mathrm{O}_{3}$ profiles in the presence of mesospheric clouds in the daytime are highly desirable to test the predictions of this model and our understanding of the genesis of mesospheric clouds.
\end{abstract}

Correspondence to: J. M. C. Plane

(j.plane@uea.ac.uk)

\section{Introduction}

Ice particles form in the high latitude mesosphere between 80 and $90 \mathrm{~km}$ during summer when temperatures fall below $150 \mathrm{~K}$ (Gadsden and Schröder, 1989; Thomas, 1991; Lübken, 1999). When these ice particles grow large enough to efficiently scatter light they become visible to groundbased observers during twilight - these spectacular "nightshining" clouds are termed noctilucent clouds (NLCs). When they are observed from the ground by lidar (Chu et al., 2003) or from space by limb-scanning satellites (Donahue et al., 1972), they are usually referred to as polar mesospheric clouds (PMCs). The ice particles that make up these clouds initially form in the vicinity of the mesopause at about $88 \mathrm{~km}$ and then sediment, dehydrating the surrounding atmosphere as they grow (von Zahn and Berger, 2003). Although much work has been done in understanding the cloud formation processes and ice aerosol particle properties, little emphasis has been placed on the role that ice particles may play in the neutral chemistry of the upper mesosphere. Only recently has this issue begun to be addressed quantitatively through laboratory and modelling studies (Murray and Plane, 2003a; Murray and Plane, 2003b; Murray, 2003; Plane et al., 2004).

This paper will focus on the impact of mesospheric ice particles on atomic oxygen, the most abundant minor atmospheric species in the upper mesosphere. Figure 1 illustrates five profiles of atomic $\mathrm{O}$ in the mesosphere and lower thermosphere (MLT), measured by rocket-borne resonance fluorescence instruments. All of these measurements were made in late July or early August, at Esrange in northern Sweden $\left(67.9^{\circ} \mathrm{N}\right)$. The rockets were launched between 00:41 and 02:23 local time (LT), when the solar-zenith angle $(\chi)$ was 92-94 (see Gumbel, 1997 for a comprehensive review of mesospheric and thermospheric $\mathrm{O}$ measurements). The pertinent details associated with each rocket flight are listed in Table 1. In all of these measurements the presence of NLC was confirmed by photometers positioned either onboard the

(C) 2005 Author(s). This work is licensed under a Creative Commons License. 
Table 1. Summary of the summer mesosphere high latitude atomic O measurements shown in Fig. 1.

\begin{tabular}{|c|c|c|c|c|c|c|}
\hline Profile & Local time & Date & $\begin{array}{l}\text { Minima } \\
\text { altitude }^{a} \\
\mathrm{~km}\end{array}$ & $\begin{array}{l}\text { Ledge scale } \\
\text { height } b \\
\mathrm{~km}\end{array}$ & $\begin{array}{l}\text { Peak }[\mathrm{O}]^{c} \\
\mathrm{~cm}^{-3}\end{array}$ & $\begin{array}{l}\text { Zenith } \\
\text { angle }\end{array}$ \\
\hline (a) - NLC-78 & $00: 41$ & $30 / 7 / 78$ & 81.8 & $0.5(82.5-85)$ & $1.6 \times 10^{12}$ & $94^{\circ}$ \\
\hline (b) - CAMP-82 & $01: 48$ & $4 / 8 / 82$ & 83.2 & $0.3(83.9-85.2)$ & $1.0 \times 10^{12}$ & $94^{\circ}$ \\
\hline (c) - CAMP-82 & 02:05 & $4 / 8 / 82$ & 83.2 & $0.5(84-85.5)$ & - & $94^{\circ}$ \\
\hline (d) - SISSI-90 & 01:05 & $26 / 7 / 90$ & 84.5 & $0.5(86-88)$ & $4 \times 10^{11}$ & $92^{\circ}$ \\
\hline (e) - NLC-93 & $02: 23$ & $2 / 8 / 93$ & 83.3 & $0.6(84-86)$ & $1.7 \times 10^{11}$ & $92^{\circ}$ \\
\hline
\end{tabular}

${ }^{a}$ The altitude at which the minima in the $\mathrm{O}$ profile below the ledge is centred.

$\mathrm{b}$ The scale height of the atomic $\mathrm{O}$ ledge between the heights in brackets

c The peak thermospheric [O].

d Zenith angle from Gumbel (1997).

(a) and (b), Dickinson, unpublished results;

(b) and (c) Kopp et al., 1985a;

(d) Ratkowski et al., 1994;

(e) Gumbel et al., 1998.

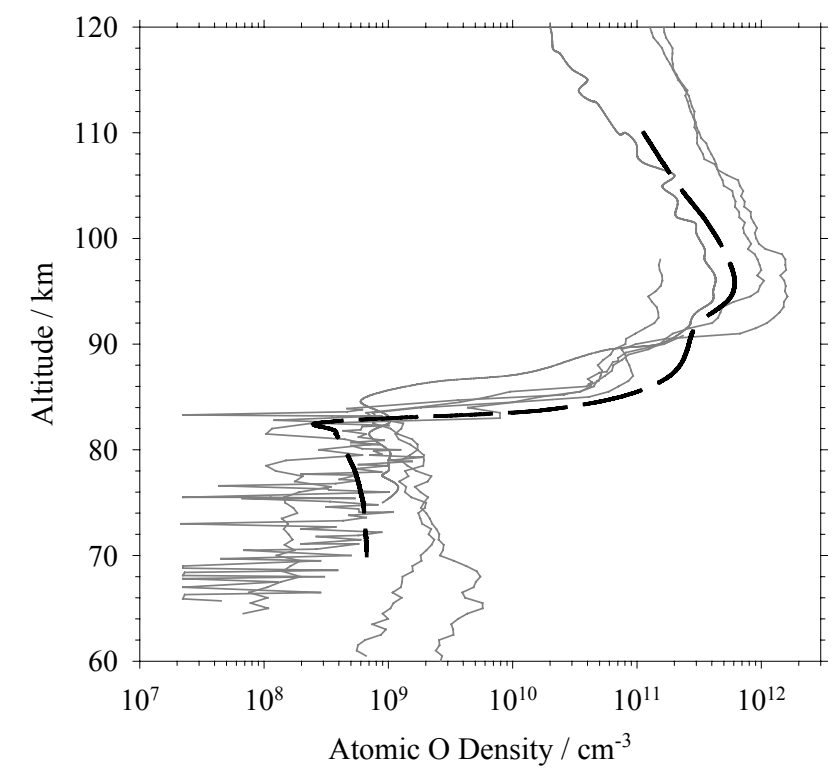

Fig. 1. Composite of the atomic $\mathrm{O}$ measurements made during summer above Esrange in Northern Sweden $\left(67.9^{\circ} \mathrm{N}\right)$ (grey lines). The pertinent details of these rocket measurements are described in Table 1. Also shown, as a dashed black line, is the modelled profile for 02:00 LT in July with no additional O loss mechanisms activated. The details of this 1-D model profile are given in Sect. 5.1.

same payload as the atomic $\mathrm{O}$ probe, or on a separate payload launched within minutes of the payload carrying the atomic O probe.

The atomic $\mathrm{O}$ profile in the sunlit MLT is characterised by a peak $\mathrm{O}$ concentration of typically $10^{11}-10^{12} \mathrm{~cm}^{-3}$ at around $95 \mathrm{~km}$. Below this peak the $\mathrm{O}$ density falls away very sharply forming what is known as the atomic O ledge, where the $\mathrm{O}$ concentration decreases by several orders of magnitude between 80 and $90 \mathrm{~km}$. The $\mathrm{O}$ concentration below the ledge, in the mesosphere, is highly variable and depends critically on factors such as the odd hydrogen density and $\chi$. The huge difference in concentration of thermospheric and mesospheric $\mathrm{O}$ can be explained in terms of photochemical lifetime of $\mathrm{O}$, which changes from just a few hours at $75 \mathrm{~km}$ to several months at $100 \mathrm{~km}$ (Brasseur and Solomon, 1984). This is because the catalytic cycles (Eqs. 1-4 and Eqs. 58) that remove $\mathrm{O}$ involve third-body reactions, the rates of which depend on the square of the atmospheric density (M), and thus decrease dramatically with increasing altitude.

$$
\begin{aligned}
& \mathrm{H}+\mathrm{O}_{2}+\mathrm{M} \rightarrow \mathrm{HO}_{2}+\mathrm{M}(\mathrm{M}=\text { third body }) \\
& \mathrm{HO}_{2}+\mathrm{O} \rightarrow \mathrm{OH}+\mathrm{O}_{2} \\
& \mathrm{OH}+\mathrm{O} \rightarrow \mathrm{H}+\mathrm{O}_{2}
\end{aligned}
$$

Net $: \mathbf{O}+\mathbf{O} \rightarrow \mathbf{O}_{2}$

$\mathrm{H}+\mathrm{O}_{3} \rightarrow \mathrm{OH}+\mathrm{O}_{2}$

$\mathrm{OH}+\mathrm{O} \rightarrow \mathrm{H}+\mathrm{O}_{2}$

$\mathrm{O}+\mathrm{O}_{2}+\mathrm{M} \rightarrow \mathrm{O}_{3}+\mathrm{M}$

Net $: \mathbf{O}+\mathbf{O} \rightarrow \mathbf{O}_{2}$

In contrast to the $\mathrm{O}$ chemical lifetime, the production of $\mathrm{O}$ from the photolysis of $\mathrm{O}_{2}$ in the Schumann-Runge continuum $(137-175 \mathrm{~nm})$ in the lower thermosphere, and in the 
Schumann-Runge bands (175-205 nm) in the mesosphere, does not vary greatly with altitude. Hence, the substantial increase of the $\mathrm{O}$ lifetime with altitude results in the atomic $\mathrm{O}$ ledge.

The rocket measurements shown in Fig. 1 were all made during twilight (when $\chi=92-94^{\circ}$, see Table 1). Under these conditions the mesosphere is still illuminated by the visible part of the spectrum since these wavelengths penetrate the dense regions of the lower atmosphere through which it has to pass. However, wavelengths less than $300 \mathrm{~nm}$ in the solar actinic flux, responsible for much of the photochemistry in the upper mesosphere, do not penetrate the lower levels of the atmosphere. Hence, the concentration of $\mathrm{O}$ below $85 \mathrm{~km}$ is very sensitive to $\chi$ and exhibits a pronounced diurnal cycle: when $\chi$ is greater than $96^{\circ}$ photochemical production of $\mathrm{O}$ ceases and the $\mathrm{O}$ rapidly forms $\mathrm{O}_{3}$ through recombination with $\mathrm{O}_{2}$ (Reaction 7) (Brasseur and Solomon, 1984). During the daytime, when $\chi$ is smaller than about $80^{\circ}$, the typical $\mathrm{O}$ concentration below $80 \mathrm{~km}$ is around $10^{10} \mathrm{~cm}^{-3}$ and the peak concentration at $95 \mathrm{~km}$ is between $10^{11}$ and $10^{12} \mathrm{~cm}^{-3}$. At the times of the rocket flights shown in Fig. 1, the concentration of $\mathrm{O}$ in the mesosphere is clearly much lower.

\section{How might the formation of mesospheric ice clouds influence atomic $O$ in the MLT?}

Mesospheric ice clouds may influence the atomic O profile in at least three ways: firstly, through the uptake of $\mathrm{O}$ on the surface of the ice particles; secondly, by redistributing water vapour, thus altering the odd hydrogen chemistry of the mesosphere; and thirdly, via the direct photolysis of the ice particles themselves to produce $\mathrm{H}$ and $\mathrm{OH}$, particularly at the base of the ice aerosol layer where the larger particles that give rise to NLC are observed.

The first of these mechanisms, initially suggested by Olivero (1974) and later by Gumbel et al. (1998), is the catalytic removal of atomic $\mathrm{O}$ on the surface of NLC ice particles. Laboratory measurements of the uptake of $\mathrm{O}$ on ice films, thought to be realistic surrogates of mesospheric ice particles, have shown that the removal of atomic $\mathrm{O}$ on ice occurs through adsorption of $\mathrm{O}$, followed by $\mathrm{O}$ or $\mathrm{O}_{2}$ in the gas phase picking the adsorbed $\mathrm{O}$ off the surface to form $\mathrm{O}_{2}$ or $\mathrm{O}_{3}$, respectively (Murray and Plane, 2003b).

The second and third mechanisms both operate through an enhanced odd hydrogen chemistry, with a corresponding increase in odd oxygen removal (Eqs. 1-8). Odd hydrogen chemistry can be enhanced in two ways: the first mechanism, originally suggested by Kopp et al. (1985a), involves the Lyman- $\alpha$ photolysis of a layer of enhanced water vapour at the base of an NLC. The source of additional $\mathrm{H}_{2} \mathrm{O}$ is thought to be the sublimation of large ice particles, which have transported $\mathrm{H}_{2} \mathrm{O}$ from higher altitudes (von Zahn and Berger, 2003). In fact, Summers et al. (2001) have used limbscanning satellite observations to show that a persistent layer of $\mathrm{H}_{2} \mathrm{O}$ vapour coexists around $\mathrm{NLC}$, where the $\mathrm{H}_{2} \mathrm{O}$ mixing ratio can be enhanced by factors of 3-4 over the background ambient levels (i.e., increased up to about $15 \mathrm{ppm}$ ). This redistribution of water vapour in the high latitude summer mesosphere results in the dehydration of the region above $84 \mathrm{~km}$ and the humidification of the region immediately below (von Zahn and Berger, 2003).

A second source of odd hydrogen species is the Lyman- $\alpha$ photolysis of the ice particles themselves, causing the ejection of a variety of hydrogen and oxygen species into the gas phase. Westley et al. (1995a and 1995b) used mass spectrometry to show that $\mathrm{OH}, \mathrm{H}_{2}, \mathrm{H}_{2} \mathrm{O}, \mathrm{HO}_{2}$ and $\mathrm{H}_{2} \mathrm{O}_{2}$ desorbed from an ice film irradiated at $121.6 \mathrm{~nm}$, over the temperature range $50-100 \mathrm{~K}$. They showed that the overall photodesorption yield (the number of molecules lost from the ice film per photon) increased significantly with temperature, and derived an effective desorption cross section of $8 \times 10^{-18} \mathrm{~cm}^{2}$ molecule ${ }^{-1}$. The absorption cross section of gas-phase $\mathrm{H}_{2} \mathrm{O}$ is $1.4 \times 10^{-17} \mathrm{~cm}^{-2}$ molecule ${ }^{-1}$, which indicates a quantum yield for photodesorption of close to unity at $121.6 \mathrm{~nm}$. Watanabe et al. (2000) irradiated $12 \mathrm{~K} \mathrm{D}_{2} \mathrm{O}$ ice at $126 \mathrm{~nm}$ and upon subsequent temperature-programmed desorption found that $\mathrm{D}_{2}$ was produced. Watanabe (private communication, Hokkaido University) speculates that reaction of $\mathrm{D}$ (produced by photolysis of $\mathrm{D}_{2} \mathrm{O}$ ) with another $\mathrm{D}$, or $\mathrm{D}_{2} \mathrm{O}$, to produce $\mathrm{D}_{2}$ only occurs efficiently at very low temperatures since at higher temperatures $\mathrm{D}$ will diffuse out of the ice structure before it has a chance to react. Yabushita et al. (2003) has recently reported that $\mathrm{H}$ atoms are produced from the surface of $90-140 \mathrm{~K}$ ice samples irradiated at $193 \mathrm{~nm}$. It is reasonable to assume that the efficiency of $\mathrm{H}$ production increases at $121 \mathrm{~nm}$, where the optical absorption cross section of water ice is much larger than at $193 \mathrm{~nm}$ (Warren, 1984). It seems clear from the available experimental data that $\mathrm{H}$ and $\mathrm{OH}$ are produced in the gas phase upon Lyman- $\alpha$ photolysis of ice, although the efficiency for production of these radicals has still to be determined.

In this paper the impact of NLC on the neutral chemistry of the mesosphere will be investigated using a 1-D photochemical model of the MLT region to evaluate these three mechanisms.

\section{The 1-D photochemical model}

The model, termed MESOMOD, is a 1-D photochemical model extending from 65 to $110 \mathrm{~km}$ with a resolution of $0.5 \mathrm{~km}$. It uses a time-implicit integration scheme (Shimazaki, 1985) with a time step of 6 min to solve the continuity equation for each species: for the $i$-th constituent of concentration $n_{i}$

$\frac{\partial n_{\mathrm{i}}}{\partial t}-Q_{\mathrm{i}}+L_{\mathrm{i}}+\frac{\partial \phi_{\mathrm{i}}}{\partial z}=0$

where $Q_{\mathrm{i}}$ and $L_{\mathrm{i}}$ are the chemical production and loss of species $i$, and $\phi_{\mathrm{i}}$ is the vertical flux. Molecular diffusion 
Table 2. The odd oxygen and hydrogen reactions included in MESOMOD.

\begin{tabular}{ll}
\hline Reaction & Rate Coefficient ${ }^{a}$ \\
\hline $\mathrm{H}+\mathrm{O}_{3} \rightarrow \mathrm{OH}+\mathrm{O}_{2}$ & $1.4 \times 10^{-10} \exp (-470 / T)$ \\
$\mathrm{OH}+\mathrm{O} \rightarrow \mathrm{H}+\mathrm{O}_{2}$ & $2.2 \times 10^{-11} \exp (-120 / T)$ \\
$\mathrm{O}+\mathrm{O}_{2}+\mathrm{M} \rightarrow \mathrm{O}_{3}+\mathrm{M}$ & $6.6 \times 10^{-34}(T / 300)^{-2.3}$ \\
$\mathrm{H}+\mathrm{O}_{2}+\mathrm{M} \rightarrow \mathrm{HO}_{2}+\mathrm{M}$ & $5.7 \times 10^{-32}(T / 300)^{-1.6}$ \\
$\mathrm{HO}_{2}+\mathrm{O} \rightarrow \mathrm{OH}+\mathrm{O}_{2}$ & $3 \times 10^{-11} \exp (-200 / T)$ \\
$\mathrm{O}+\mathrm{O}_{3} \rightarrow 2 \mathrm{O}_{2}$ & $8 \times 10^{-12} \exp (-2065 / T)$ \\
$\mathrm{OH}+\mathrm{HO}_{2} \rightarrow \mathrm{H}_{2} \mathrm{O}+\mathrm{O}_{2}$ & $4.8 \times 10^{-11} \exp (-250 / T)$ \\
$\mathrm{H}+\mathrm{HO}_{2} \rightarrow 2 \mathrm{OH}$ & $8.1 \times 10^{-11} \times 0.9$ \\
$\mathrm{H}+\mathrm{HO}_{2} \rightarrow \mathrm{H}_{2}+\mathrm{O}$ & $8.1 \times 10^{-11} \times 0.1$ \\
$\mathrm{O}^{1} \mathrm{D}+\mathrm{H}_{2} \mathrm{O} \rightarrow 2 \mathrm{OH}$ & $2.2 \times 10^{-10}$ \\
$\mathrm{O}^{1} \mathrm{D}+\mathrm{N}_{2} \rightarrow \mathrm{O}+\mathrm{N}_{2}$ & $1.8 \times 10^{-11} \exp (-110 / T)$ \\
$\mathrm{O}^{1} \mathrm{D}+\mathrm{O}_{2} \rightarrow \mathrm{O}+\mathrm{O}_{2}$ & $3.2 \times 10^{-11} \exp (-70 / T)$ \\
$\mathrm{O}^{1} \mathrm{D}+\mathrm{H}_{2} \rightarrow \mathrm{OH}+\mathrm{H}$ & $1.1 \times 10^{-10}$ \\
$\mathrm{OH}+\mathrm{OH} \rightarrow \mathrm{H}_{2} \mathrm{O}+\mathrm{O}_{2}$ & $4.2 \times 10^{-12} \exp (-240 / T)$ \\
$\mathrm{OH}+\mathrm{OH}_{2} \rightarrow \mathrm{H}_{2} \mathrm{O}_{2}$ & $6.2 \times 10^{-31}(-T / 300)^{-1}$ \\
$\mathrm{OH}+\mathrm{H}_{2} \mathrm{O}_{2} \rightarrow \mathrm{H}_{2} \mathrm{O}+\mathrm{HO}_{2}$ & $2.9 \times 10^{-12} \exp (-160 / T)$ \\
$\mathrm{HO}+\mathrm{O}_{3} \rightarrow \mathrm{OH}+2 \mathrm{O}_{2}$ & $1.1 \times 10^{-14} \exp (-500 / T)$ \\
$\mathrm{OH}+\mathrm{O}_{3} \rightarrow \mathrm{HO}+\mathrm{O}_{2}$ & $1.6 \times 10^{-12} \exp (-940 / T)$ \\
$\mathrm{HO}+\mathrm{HO}_{2} \rightarrow \mathrm{H}_{2} \mathrm{O}_{2}+\mathrm{O}_{2}$ & $2.3 \times 10^{-13} \exp (-600 / T)$ \\
$\mathrm{O}+\mathrm{H}_{2} \mathrm{O}_{2} \rightarrow \mathrm{OH}+\mathrm{HO}_{2}$ & $1.4 \times 10^{-12} \exp (-2000 / T)$ \\
$\mathrm{OH}+\mathrm{H}_{2} \rightarrow \mathrm{H}_{2} \mathrm{O}+\mathrm{H}$ & $5.5 \times 10^{-12} \exp (-2000 / T)$ \\
\hline
\end{tabular}

${ }^{a}$ Rate coefficient units: bimolecular, $\mathrm{cm}^{3}$ molecule ${ }^{-1} \mathrm{~s}^{-1}$; termolecular, $\mathrm{cm}^{6}$ molecule ${ }^{-2} \mathrm{~s}^{-1}$; the rate constants were taken from Sander et al. (2003).

dominates vertical transport above the turbopause, which is at about $95 \mathrm{~km}$ in the polar summer MLT (Lübken, 1997), whereas bulk mixing, parameterised by the vertical eddy diffusion coefficient, $K_{\mathrm{zz}}$, dominates below:

$\phi_{\mathrm{i}}=-\left(K_{\mathrm{zz}}+D_{\mathrm{i}}\right)\left\{\frac{\partial n_{\mathrm{i}}}{\partial z}+\left(\frac{1}{T} \frac{\partial T}{\partial z}+\frac{1}{H_{\mathrm{A}}}\right) n_{\mathrm{i}}\right\}$,

where

$\frac{1}{H_{\mathrm{A}}}=\frac{1}{K_{\mathrm{zz}}+D_{\mathrm{i}}}\left(\frac{K_{\mathrm{zz}}}{\bar{H}}+\frac{D_{\mathrm{i}}}{H_{\mathrm{i}}}\right)$

with $\bar{H}$ and $H_{\mathrm{i}}$ being the scale height of the atmosphere and the $i$-th constituent, respectively, and $D_{\mathrm{i}}$ the molecular diffusion coefficient.

The model includes a full treatment of the odd hydrogen and oxygen species, the reactions and rate coefficients of which are listed in Table 2. The rate constants are taken from a recent evaluation (Sander et al., 2003). Parameterisation for the photolysis rates of $\mathrm{O}_{2}$ in the Schumann-Runge bands

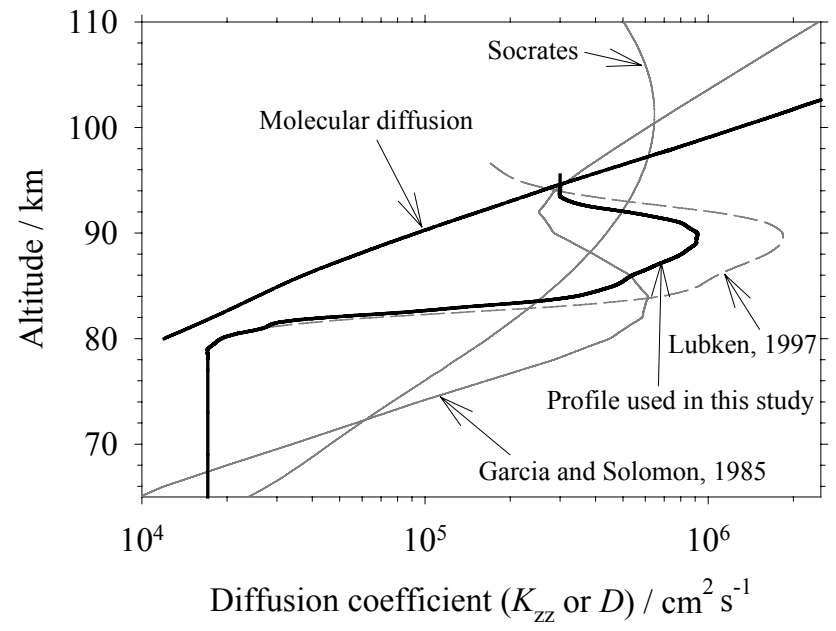

Fig. 2. Composite of various eddy diffusion coefficient $\left(K_{\mathrm{Zz}}\right)$ profiles, including that derived from high latitude summer mesosphere neutral-turbulence measurements (Lübken, 1997) (dashed line), the results from the 2-D models of Garcia and Solomon (1985) and the NCAR SOCRATES 2-D model of the middle atmosphere (Khosravi et al., 2002). Also shown is the profile used in this study and the molecular diffusion given the temperature profile for July, both shown with heavy solid lines.

(SRB) and Schumann-Runge continuum (SRC) are taken from Murtagh (1988) and Brasseur and Solomon (1984), respectively. The photolysis rate of $\mathrm{H}_{2} \mathrm{O}$ in the SchumannRunge bands (SRB) and at the Lyman- $\alpha$ line are calculated using the parameterisations given by Brasseur and Solomon (1984) and a parameterisation for the $\mathrm{O}_{2}$ column density as a function of solar zenith angle is taken from Shimazaki (1985). Profiles of pressure and temperature were taken from a 2-D global circulation model (Garcia and Solomon, 1994).

At the upper boundary an additional flux of $\mathrm{O}$ is included, which results from the downward transport of thermospheric $\mathrm{O}$. This flux is estimated from the following expression (Shimazaki 1985):

$\phi_{\mathrm{i}}=D_{\mathrm{i}}\left(\frac{1}{\bar{H}}-\frac{1}{H_{\mathrm{i}}}\right)[\mathrm{O}]$

where $H_{\mathrm{i}}$ is the scale height of $\mathrm{O}$ at $110 \mathrm{~km}$ (typically $15 \mathrm{~km}), \bar{H}$ is about $7 \mathrm{~km}$ (Hedin, 1991), [O $]_{\mathrm{i}}$ is typically $2 \times 10^{11} \mathrm{~cm}^{-3}$ (Gumbel, 1997), and $D_{\mathrm{i}}$ is $5 \times 10^{6} \mathrm{~cm}^{2} \mathrm{~s}^{-1}$. This implies a flux into the top level of the model of $7.4 \times 10^{11} \mathrm{~cm}^{-2} \mathrm{~s}^{-1}$; this corresponds to a production term in the top box of $1.5 \times 10^{7} \mathrm{~cm}^{-3} \mathrm{~s}^{-1}$, compared with midday photochemical production of only $1.5 \times 10^{5} \mathrm{~cm}^{-3} \mathrm{~s}^{-1}$. Addition of this thermospheric flux increases the peak $\mathrm{O}$ concentration at $95 \mathrm{~km}$ from $1 \times 10^{11} \mathrm{~cm}^{-3}$ to $7 \times 10^{11} \mathrm{~cm}^{-3}$, which places the model in very good agreement with rocket measurements (see Fig. 1). 


\section{Tuning the eddy diffusion profile}

The $K_{\mathrm{zz}}$ profile used in this study was adapted from a $K_{\mathrm{zz}}$ profile derived from rocket-borne neutral density fluctuation measured in the summer high latitude MLT at $70^{\circ} \mathrm{N}$ (Lübken, 1997). Lübken found that significant turbulence during this period only occurred between 78 and $97 \mathrm{~km}$, peaking around $90 \mathrm{~km}$. Later rocket measurements confirmed these results [Lübken et al., 2002]. Figure 2 shows that this is in contrast to the predictions of 2-D models, which predict a much broader region of turbulence extending from $70 \mathrm{~km}$ to above $110 \mathrm{~km}$.

While it was possible to derive the vertical extent of turbulence accurately from the measurements, Lübken notes that the derivation of $K_{\mathrm{zz}}$ is only accurate to within a factor of two. In fact, for the modelling results presented below, the $K_{\text {zz }}$ profile used was that of Lübken (1997) reduced by a factor of two (see Fig. 2). Using the unaltered Lübken $K_{\text {zz }}$ profile caused the concentration of $\mathrm{O}$ in the region of maximum turbulence, at about $90 \mathrm{~km}$, to be significantly reduced compared with the rocket $O$ profiles. The black dashed line in Fig. 1 illustrates the model prediction at 02:00 LT with the Lübken $K_{\mathrm{zz}}$ profile reduced by a factor of two - it is clearly in good agreement with the rocket profiles.

\section{Results and discussion}

The model results presented here are for 02:00 and 14:00 LT in July. These times were chosen for two reasons. The first is that the night-time model run corresponds closely to the launch times of the rocket measurements. The second is that the largest ice particles and largest water vapour enhancements are expected at around 02:00 and 14:00 LT, because of the effect of the semi-diurnal tide (von Zahn and Berger, 2003).

\subsection{Atomic $\mathrm{O}$ in the absence of ice particles}

The modelled atomic $\mathrm{O}$ profile for July is shown as a function of local time in Fig. 3. The effect of attenuating vacuum ultraviolet radiation at large $\chi$ is clear at altitudes below $84 \mathrm{~km}$, where [O] is reduced at night. However, throughout the NLC season at $70^{\circ} \mathrm{N}$ the mesosphere is never completely in darkness, so that photolysis proceeds at a sufficient rate to produce concentrations of $\mathrm{O}$ greater than $10^{8} \mathrm{~cm}^{-3}$ in the mesosphere.

Comparison of the modelled O profile at 02:00 LT with the rocket measurements, illustrated in Fig. 1, shows that the main features of the $\mathrm{O}$ profile are satisfactorily reproduced. The model reproduces the peak [O], the altitude of the peak $[\mathrm{O}]$, and the steep scale height of $\approx 0.5 \mathrm{~km}$ common to all the rocket measurements between 83 and $86 \mathrm{~km}$. Below $83 \mathrm{~km}$, the modelled [O] $\left(4 \times 10^{8} \mathrm{~cm}^{-3}\right)$ falls within the natural variability of $[\mathrm{O}]$ in the atmosphere. Interestingly, the minimum in the modelled $\mathrm{O}$ profile occurs at $84 \mathrm{~km}$, very close to the

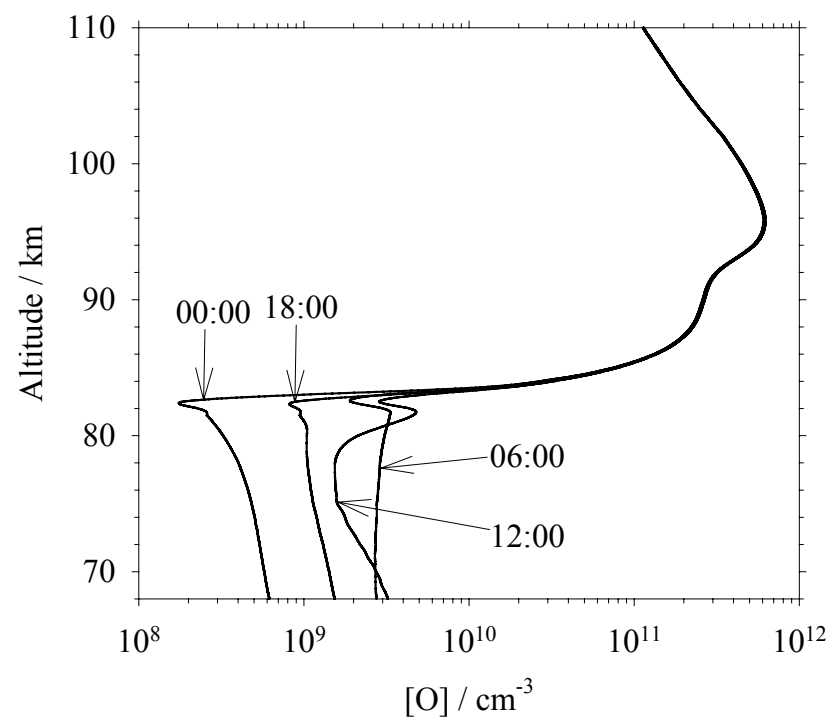

Fig. 3. The model $\mathrm{O}$ profile at $6 \mathrm{~h}$ intervals in July with an unperturbed odd hydrogen and water vapour profile and no uptake on the ice particles.

altitude at which minima were observed in the rocket measurements (see Fig. 1 and Table 1). This feature, which has stimulated various groups to suggest possible interactions between O and NLC (Sect. 1) may simply be a product of the unique photochemical environment at the altitude range where NLC occur. Previous photochemical models of the summer mesosphere (e.g., Xu et al. (2001) and Ratkowski et al. (1994)), have also predicted a minimum in $\mathrm{O}$ at about $84 \mathrm{~km}$.

The minimum at $84 \mathrm{~km}$ in the model arises from the relative chemical lifetimes of the odd oxygen $\left(\mathrm{O}_{\mathrm{x}}\right)$ and odd hydrogen $\left(\mathrm{HO}_{\mathrm{x}}\right)$ families in this region. Like $\mathrm{O}$ (the dominant $\mathrm{O}_{\mathrm{x}}$ species above $75 \mathrm{~km}$ ), the chemical lifetime of the $\mathrm{HO}_{\mathrm{x}}$ family, which is orders of magnitude longer than the chemical lifetimes of $\mathrm{H}, \mathrm{OH}$ or $\mathrm{HO}_{2}$, increases dramatically with altitude above about $80 \mathrm{~km}$ (Brasseur and Solomon, 1984). However, there is one significant difference: the region in which $\mathrm{HO}_{\mathrm{x}}$ rapidly increases in concentration, called the $\mathrm{HO}_{\mathrm{x}}$ ledge by analogy with $\mathrm{O}$, occurs at a lower altitude than the $\mathrm{O}$ ledge. At midnight in July, $\left[\mathrm{HO}_{\mathrm{x}}\right]$ increases dramatically by a factor of about 25 between 82 and $82.5 \mathrm{~km}$ (Fig. 4), whereas at noon the ledge is not so pronounced, with $\left[\mathrm{HO}_{\mathrm{x}}\right]$ increasing by just a factor of two over a similar altitude range. This diurnal variation, driven by the attenuation of UV radiation at high $\chi$, is clearly shown in Fig. 4. The region above $84 \mathrm{~km}$ experiences no appreciable diurnal cycle because the lifetime of $\mathrm{HO}_{\mathrm{x}}$ is larger than a day. It is clear from Fig. 4 that the $\mathrm{O}$ ledge occurs about $1-2 \mathrm{~km}$ above that of the $\mathrm{HO}_{\mathrm{x}}$ ledge, and it is within the region between the ledges that the minimum in $\mathrm{O}$ is generated due to the locally enhanced $\mathrm{HO}_{\mathrm{x}}$ chemistry (Eqs. 1-8). 

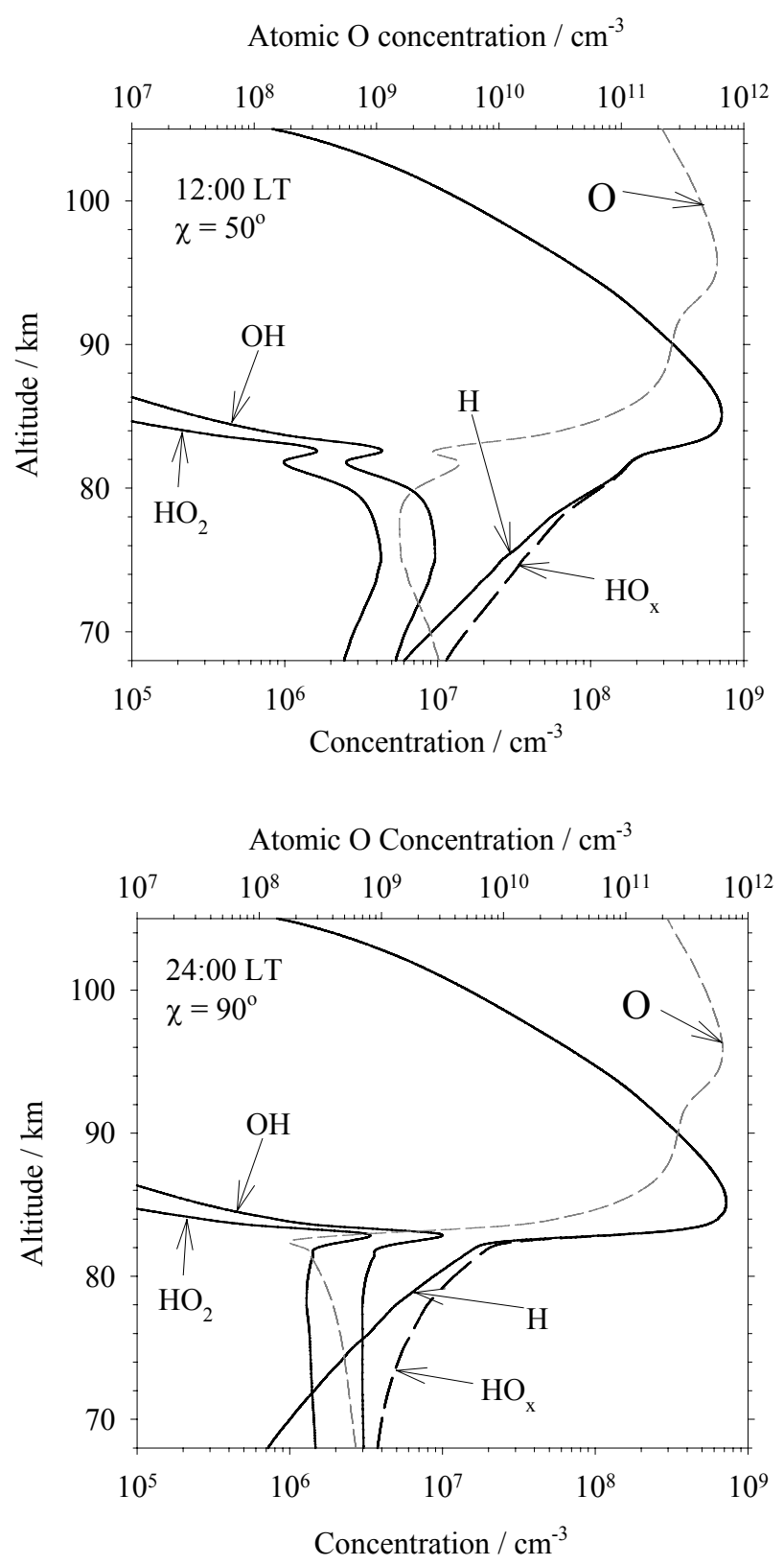

Fig. 4. The model odd hydrogen family and its constituents at 12:00 LT (top) and 24:00 LT (bottom). Also shown, as a grey dashed line, is the model O profile at 12:00 LT and 24:00 LT, respectively.

The minimum in $\mathrm{O}$ below the ledge is reinforced by the severe attenuation of Lyman- $\alpha$ radiation below $80 \mathrm{~km}$ at high $\chi$, which results in the peak $\mathrm{HO}_{\mathrm{x}}$ production rate to shift from $75 \mathrm{~km}$, during the daytime, to $84 \mathrm{~km}$. This has the result of causing the greatest removal of $\mathrm{O}$ just beneath the $\mathrm{O}$ ledge. As a consequence of the minimum in $\mathrm{O}$ at around $83 \mathrm{~km}$, the partitioning within the $\mathrm{HO}_{\mathrm{x}}$ family is altered in such a way as to favour $\mathrm{OH}$ and $\mathrm{HO}_{2}$. Thus a peak concentration of these species is observed in the model (Fig. 4).

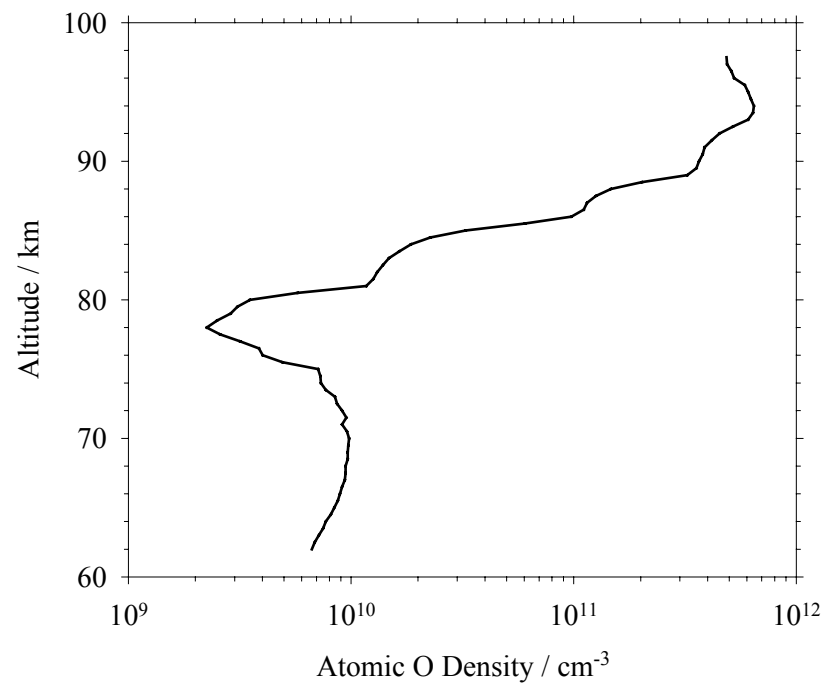

Fig. 5. High $\chi$ atomic $\mathrm{O}$ profile measured by rocket-borne resonance fluorescence instruments where ice particles do not exist. This profile was measured at 05:25 on 3 April 1974 by a rocket-borne resonance fluorescence/absorption probe launched from South Uist $\left(57.4^{\circ} \mathrm{N}\right.$ and $7.4^{\circ} \mathrm{W}$ ) while $\chi=95^{\circ}$ (Dickinson et al., 1980).

These effects at large $\chi$ should not of course be restricted to the season and regions in which ice particles form. Unfortunately there appears to be only one $\mathrm{O}$ measurement that has been made with $\chi>90^{\circ}$ in the absence of ice particles (see the review by Gumbel (1997)). This O profile was measured at 05:25 LT on the 3 April 1974 with a resonance fluorescence/absorption probe on board a rocket launched from South Uist $\left(57.4^{\circ} \mathrm{N}\right.$ and $7.4^{\circ} \mathrm{W}$ ) while $\chi=95^{\circ}$ (Dickinson et al., 1980). This profile exhibits a distinct minimum just below 80 km, as shown in Fig. 5.

\subsection{Impact of heterogeneous uptake of atomic $\mathrm{O}$ on ice par- ticles}

A lower limit to uptake coefficient, $\gamma$, required to produce a significant depletion in the atomic $\mathrm{O}$ profile, can be derived using the MESOMOD model by including a cloud particle surface area profile derived from a detailed cloud microphysics model (von Zahn and Berger, 2003). The profile of the cloud surface area shown in Fig. 6 is calculated assuming a normal size distribution where the width of the distribution is equal to $0.23 r_{\text {mean }}\left(r_{\text {mean }}=\right.$ mean particle radius) (Berger and von Zahn, 2002). The first-order rate coefficient for uptake of $\mathrm{O}$ on the ice surface is then given by:

$k_{\text {het }}=\frac{1}{4} \bar{c} A \varepsilon\left(\gamma_{i}+\gamma_{i i}\right)$,

where $\bar{c}$ is the root-mean-square velocity of $\mathrm{O}, A$ is the volumetric surface area assuming smooth spherical particles, and $\varepsilon$ is a factor to increase the surface area to account for the non-spherical nature of mesospheric ice particles and surface 

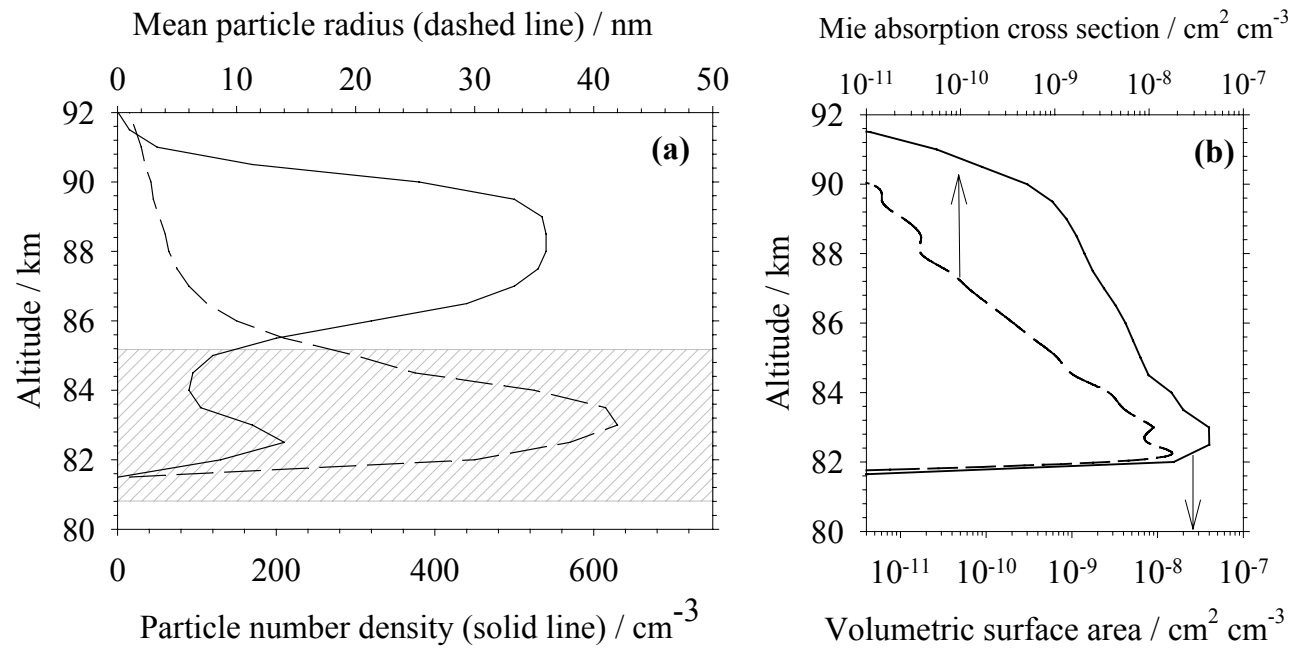

Fig. 6. (a) The particle number density and radius in the summer mesosphere at $70^{\circ} \mathrm{N}$ from a microphysical model (von Zahn and Berger, 2003). (b) The volumetric surface area (solid line) and Mie scattering cross section (dashed line) as a function of altitude for the mean particles radii and number densities in Fig. 6a assuming a normal size distribution.

roughness. The product $\mathrm{A} \varepsilon$ is therefore the total volumetric surface area. $\gamma_{i}$ is the uptake coefficient of $\mathrm{O}$ on type $i$ sites, where the adsorbed $\mathrm{O}$ then reacts with gas-phase $\mathrm{O}$ to produce $\mathrm{O}_{2}$; and $\gamma_{i i}$ is the uptake coefficient of $\mathrm{O}$ on disordered type ii sites, where the adsorbed $\mathrm{O}$ reacts with gas-phase $\mathrm{O}_{2}$ to produce $\mathrm{O}_{3}$ (Murray and Plane, 2003). The experimentally determined uptake coefficients are:

$\gamma_{i}=1.5 \times 10^{-10} \exp \left(11.4 \mathrm{~kJ} \mathrm{~mol}^{-1} / R T\right)\left[\mathrm{O}_{2}\right]$

$\gamma_{i i}=7 \times 10^{-6}$

However, it should be noted that the uptake on type $i$ sites produces $\mathrm{O}_{3}$, and since $\mathrm{O}$ is in photochemical equilibrium with $\mathrm{O}_{3}$, the loss of $\mathrm{O}$ on type $i$ sites will not create a local depletion of $\mathrm{O}$.

An estimated upper limit to $\varepsilon$ of five has been used in this modelling study, for the following reasons. Lidar measurements with polarised light have shown that NLC particles are non-spherical with length-over-diameter ratios of at least 2.5 (Baumgarten et al., 2002). In the troposphere the aspect ratio of ice needles has been measured to be as large as 33 (Young, 1993). Assuming a length over width ratio of 2.5 gives a surface area enhancement over a sphere of equal volume of $\varepsilon=1.25$, while that of a particle with a length over width ratio of 33 gives $\varepsilon=2.5$. Additional surface area may be available if the surface of the mesospheric ice particles are rough. Studies of ice films deposited above $200 \mathrm{~K}$ show that surface area estimates from adsorption isotherms give very similar surface areas to measurements by electron microscopy (Keyser and Leu, 1993). This result shows that above $200 \mathrm{~K}$ the large surface area of these ice films is entirely due to structures on the scale of microns, since this is the resolution of the microscopes used and smaller structures would be detected by gas adsorption measurements. Keyser and Leu (1993) postulate the Kelvin effect to be responsible for the lack of sub-micron structures. At much lower temperatures, the formation of surfaces with a larger degree of curvature will be stable, but for NLC particles significant surface roughness is unlikely since the particles themselves are already on the scale of a few tens of nanometers $(r>20 \mathrm{~nm})$. Surface roughness would have to be on a smaller scale than this. It is believed that micropores, structures on the scale of nanometers, do not exist above about $110 \mathrm{~K}$ in ice films, and therefore such structures are unlikely to exist in NLC ice particles. Hence, $\varepsilon=5$ seems a generous upper limit and appropriate for testing the potential impact of NLC on the atomic O profile.

The model shows that the measured uptake rates on ice are too small to influence the $\mathrm{O}$ concentration in the summer mesosphere. In fact, with $\varepsilon=5, \gamma\left(=\gamma_{i}+\gamma_{i}\right)$ needs to be 0.05 before a significant reduction in the $\mathrm{O}$ concentration at the base of the cloud layer is observed. Figure 7 illustrates the modelled $O$ profile for $\gamma=0,0.1$ and 1 as well as the two rocket profiles which appear to be least perturbed by the action of gravity waves. Note that although the rocket $[\mathrm{O}]$ below the ledge is larger than the model [O], there is reasonable agreement within the limits of the natural variability (see Fig. 1). When $\gamma=0.1$ the model reproduces the rocketmeasured ledge and minima rather well, but when $\gamma$ is set at unity the uptake in the upper part of the ice cloud becomes significant, the ledge is shifted upwards and the minimum is much deeper and wider than in the measured profiles. If $\varepsilon=5, \gamma$ must be larger than 0.05 in order to have a significant impact on [O], but not larger than 0.3 or too great a perturbation results. Hence, $\gamma$ would need to be at least $5 \times 10^{3}$ times larger than the laboratory measured value. We therefore conclude that heterogeneous uptake of atomic $\mathrm{O}$ on ice particles is not an important process in the summer mesosphere. 


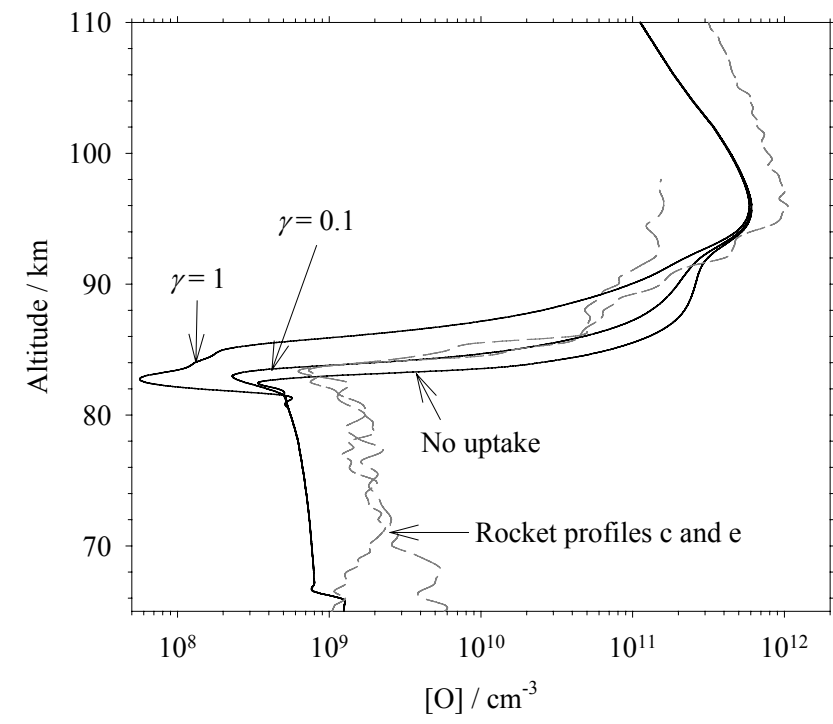

Fig. 7. The calculated $O$ profile for no uptake on ice and for overall uptake coefficients of 0.1 and 1 at 02:00 LT. Also shown are the two rocket profiles (c and e, see Table 1) least perturbed by gravity waves (grey dashed lines). The surface area enhancement $\varepsilon=5$.

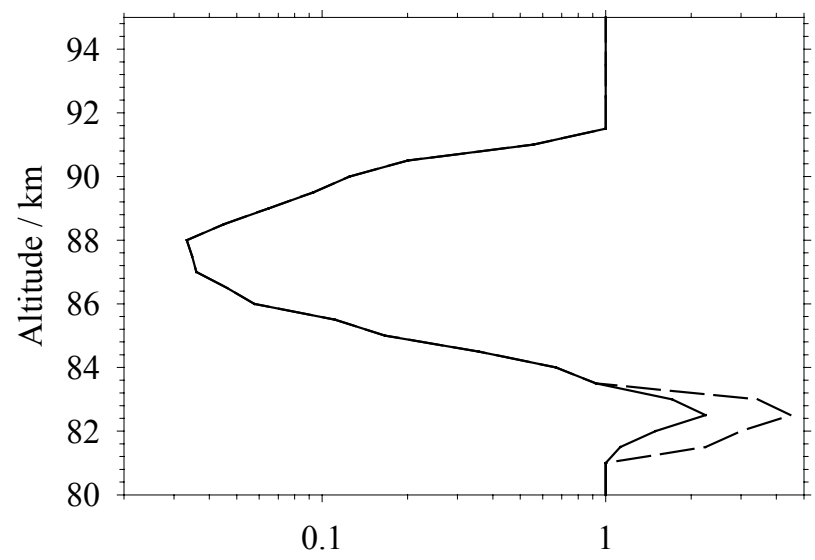

Enhancement/depletion factor $\left(Z_{\mathrm{H} 2 \mathrm{O}}\right)$

Fig. 8. The impact of ice particle formation on the distribution of water vapour in the summer mesosphere at 14:00 LT and $69^{\circ} \mathrm{N}$, expressed in terms of an enhancement/depletion factor, $Z_{\mathrm{H}_{2} \mathrm{O}}$. This factor is derived by comparing Fig. 4, the water distribution in the absence of ice particles, and Fig. 9, the water distribution in the presence of ice particles, in von Zahn and Berger (2003). The dashed line represents the water vapour enhancements in line with the satellite limb scanning measurements of Summers et al. (2001).

5.3 Impact of the modified water vapour profile in the presence of ice clouds

The detailed microphysical model of Berger and von Zahn (2002) clearly demonstrates that the $\mathrm{H}_{2} \mathrm{O}$ mixing ratio is dramatically altered by the formation and transport of water ice particles (Fig. 8). Ice particles nucleate close to the

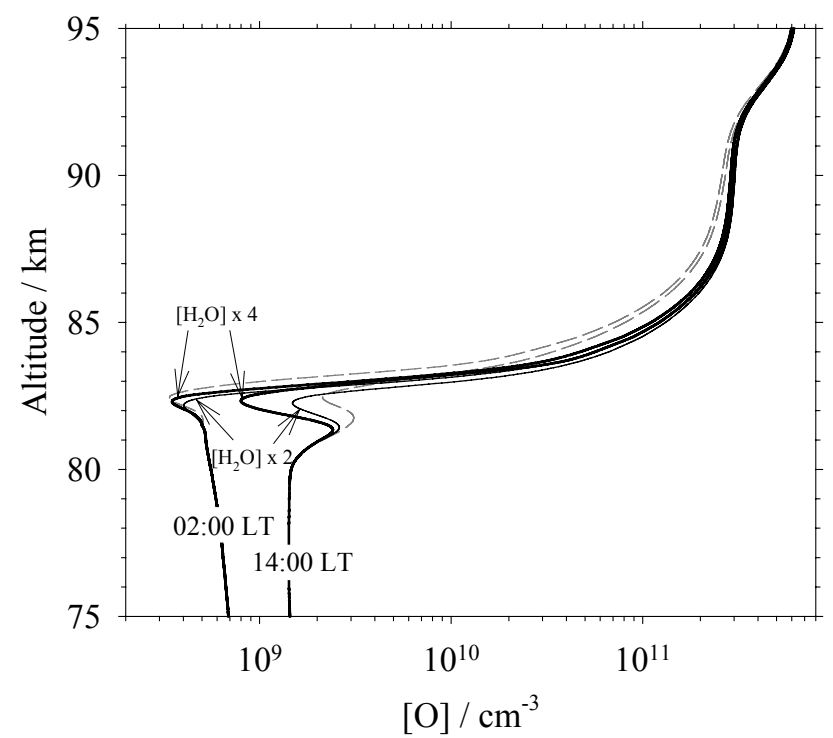

Fig. 9. The atomic $\mathrm{O}$ profile with a modified water vapour profile at 02:00 and 14:00 LT, when the largest water vapour enhancements are expected. $Z_{\mathrm{H}_{2} \mathrm{O}}$ shown in Fig. 8 was used directly for the calculated profiles marked $\left[\mathrm{H}_{2} \mathrm{O}\right] \times 2$ (light solid lines), where the peak enhancement was about two. For the profiles marked $[\mathrm{H} 2 \mathrm{O}] \times 4$ (heavy solid lines) all values of $Z_{\mathrm{H}_{2} \mathrm{O}}>1$ were increased by a factor of two, so that the peak enhancement was about 4 . The dashed grey lines represent the $\mathrm{O}$ profile for an unperturbed water vapour profile.

mesopause $(88-90 \mathrm{~km})$ where they may grow and sediment through the upper mesosphere dehydrating the region as they descend, so that the mixing ratio can fall to less than $0.3 \mathrm{ppm}$ above $85 \mathrm{~km}$ - about $10 \%$ of the mixing ratio if no ice particles were present. von Zahn and Berger (2003) show that it takes on the order of $10 \mathrm{~h}$ for ice particles to grow large enough to scatter light efficiently and become optically detectable as NLC. They also state that the build-up of water vapour at $83 \mathrm{~km}$ can only start after large particles, that give rise to visible NLC, have formed. Hence, NLC are an indication for the presence of large, sublimating ice particles. It is interesting to note that the water vapour layer between 81.5 and $83 \mathrm{~km}$ occurs at the altitude of the visible NLC rather than below (Fig. 6). The microphysical model of von Zahn and Berger includes the effect of tides. The semidiurnal tide causes the ice particles to sublimate when the vertical tidal wind direction reverses from down to up. The mixing ratio in the regions of enhanced $\mathrm{H}_{2} \mathrm{O}$ can be as large as $13 \mathrm{ppm}$, an enhancement factor (designated as $Z_{\mathrm{H} 2 \mathrm{O}}$ ) of about three over the unperturbed $\mathrm{H}_{2} \mathrm{O}$ density (von Zahn and Berger, 2003). This model prediction is in good accord with the satellite observations of Summers et al. (2001), where a maximum $Z_{\mathrm{H} 2 \mathrm{O}}$ value of almost four was recorded.

The redistribution of water vapour in the summer mesosphere by ice particles will affect the mesospheric odd hydrogen distribution, since the UV photolysis of $\mathrm{H}_{2} \mathrm{O}$ is the 
main source of odd hydrogen species. This is illustrated in Fig. 9, which shows the impact on the $\mathrm{O}$ profile when the $\mathrm{H}_{2} \mathrm{O}$ profile is modified. Two $Z_{\mathrm{H}_{2} \mathrm{O}}$ profiles were used for this modelling, the first was the profile shown in Fig. 8 that is taken from the model of Berger and von Zahn (2002), where the peak $Z_{\mathrm{H}_{2} \mathrm{O}}$ was about two (solid line in Fig. 8); the second was the same profile, but where all values of $Z_{\mathrm{H}_{2} \mathrm{O}}>1$ were multiplied by two to bring the $\mathrm{H}_{2} \mathrm{O}$ enhancement in line with the measurements of Summers et al. (2001) (dashed line in Fig. 8).

The model calculations with the smaller peak $Z_{\mathrm{H}_{2} 0}$ will be considered first (light black lines in Fig. 9). Comparison against the standard $\mathrm{O}$ profile (grey dashed line - the $\mathrm{O}$ profile with an unperturbed water profile and no uptake on the ice) reveals that the reduction in $\mathrm{H}_{2} \mathrm{O}$ and therefore $\mathrm{H}$ and $\mathrm{OH}$ is sufficient to cause an increase in the concentration of $\mathrm{O}$ in the region where $Z_{\mathrm{H}_{2} \mathrm{O}}<1$. At 02:00 LT the photolysis rate of $\mathrm{H}_{2} \mathrm{O}$ at $82-83 \mathrm{~km}$ is not sufficient to create a depletion in $\mathrm{O}$, because Lyman- $\alpha$ is significantly attenuated. However, the Lyman- $\alpha$ intensity is almost unaltered $2 \mathrm{~km}$ higher, hence there is a similar enhancement in the atomic $\mathrm{O}$ profile above this altitude both at 02:00 and 14:00 LT.

The calculations with the larger peak $Z_{\mathrm{H}_{2} \mathrm{O}}$ (heavy solid lines) show that at 14:00 LT, when Lyman- $\alpha$ penetrates deeper into the atmosphere, the photolysis of $\mathrm{H}_{2} \mathrm{O}$ creates a rather striking depletion in $\mathrm{O}$ at $83 \mathrm{~km}$. There are, to date, no rocket measurements to confirm this result. The odd hydrogen production is only rapid enough to enhance the loss of O significantly when $\chi$ is less than $80^{\circ}$, which happens in July between about 04:00 and 20:00 LT at $70^{\circ} \mathrm{N}$.

\subsection{Impact of the photolysis of large ice particles}

A large proportion of the water between 80 and $90 \mathrm{~km}$ in the summer mesosphere is in the form of water ice particles. In fact, for a typical mean radius of $42 \mathrm{~nm}$ and number density of $200 \mathrm{~cm}^{-3}$ at $83 \mathrm{~km}$ (Fig. 6a), the equivalent water vapour mixing ratio is $9 \mathrm{ppm}$, assuming a density of $0.9 \mathrm{~g} \mathrm{~cm}^{-3}$ for low-temperature ice. That is, a significant quantity of water has been concentrated into a relatively narrow layer. Thus, if the Lyman- $\alpha$ photolysis of the ice particles and subsequent release of $\mathrm{H}$ and $\mathrm{OH}$ into the gas phase were an efficient process, the odd oxygen chemistry may be perturbed.

Although NLC ice particles are small compared to the wavelength of Lyman- $\alpha$ radiation, the Mie absorption efficiency at $121.6 \mathrm{~nm}$ for spherical ice particles with radii greater than $30 \mathrm{~nm}$ approaches unity. The Mie calculations used in this study were performed with the code of Espy and Jutt (2002), using the refractive index for ice from Warren (1984).

The volumetric Mie absorption cross section (units of $\mathrm{cm}^{2}$ $\mathrm{cm}^{-3}$ ), calculated assuming a normal distribution of ice particles and using the Mie absorption cross section for the particle distribution shown in Fig. 6a, is illustrated in Fig. 6b. For this modelling study we have assumed that each absorbed

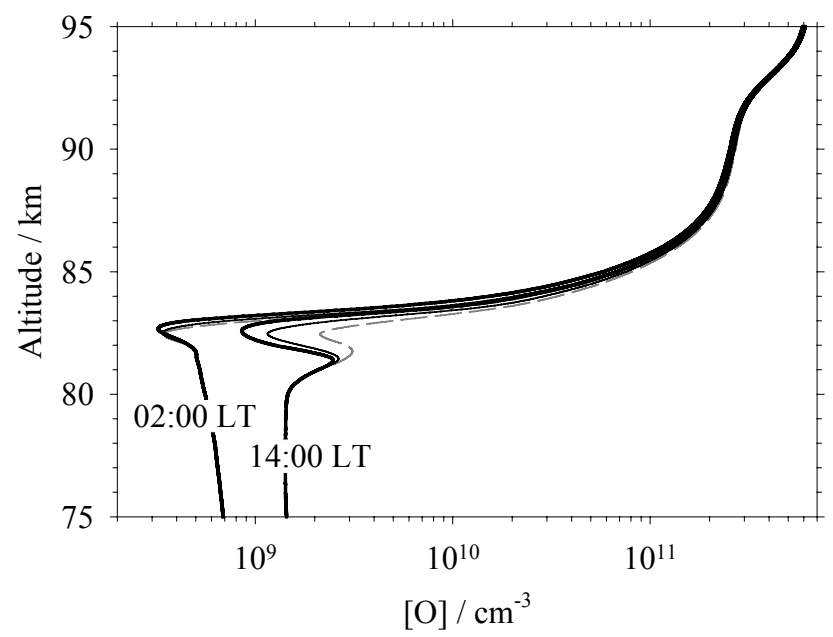

Fig. 10. The calculated $O$ profile including the effect of ice photolysis, for 02:00 and 14:00 LT, with the particle size and number density profile shown in Fig. 6 (light solid line) and where the particle radius was increased by a factor of 1.5 (heavy solid line). The $\mathrm{O}$ profile in the absence of an ice cloud is included for reference (dashed line).

photon results in the ejection of one $\mathrm{H}$ atom and one $\mathrm{OH}$ radical into the gas phase. The resulting modelled $\mathrm{O}$ profiles are represented by the light solid lines in Fig. 10. The effect is negligible at night because the Lyman- $\alpha$ intensity is small, but there is a clear depletion between 82 and $84 \mathrm{~km}$ in the 14:00 LT profile.

The heavy solid lines in Fig. 10 represent upper limits to the impact of ice photolysis on the O profile. In this case the particle mean radius has been increased to $64 \mathrm{~nm}$ : the water vapour mixing ratio equivalent of this cloud is now $20 \mathrm{ppm}$, which requires all the $\mathrm{H}_{2} \mathrm{O}$ from 80 to $90 \mathrm{~km}$ to be deposited within a $1.5 \mathrm{~km}$ layer. The effect of this cloud on the atomic O profile is clear when $\chi$ is less than $80^{\circ}$, whereas the impact at night remains negligible.

\section{Impact of ice particles on the neutral chemistry of the mesosphere}

In the preceding sections it has been shown that the odd hydrogen chemistry of the mesosphere is substantially modified by the formation of ice particles. The focus of this paper so far has been the effect of this on atomic $\mathrm{O}$, but the impact on the minor $\mathrm{HO}_{\mathrm{x}}, \mathrm{O}_{\mathrm{x}}$ and related species should also be considered. Figure 11 shows the impact of the modified $\mathrm{H}_{2} \mathrm{O}$ profile (using the upper limit to $Z_{\mathrm{H}_{2} \mathrm{O}}$, shown as the dashed line in Fig. 8) on a number of species at 14:00 LT in July. The effect of ice photolysis has not been included in this model run because there cannot simultaneously be a concentrated layer of water vapour and ice particles, since the available supply of $\mathrm{H}_{2} \mathrm{O}$ would then be exceeded. Of course, the two mechanisms can operate together, each at a reduced rate. At 


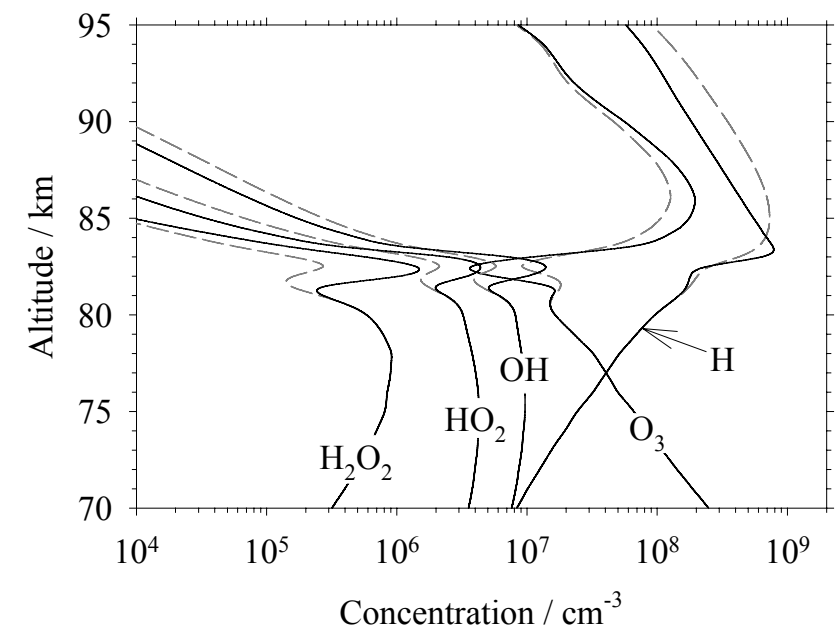

Fig. 11. The calculated profiles for 14:00 LT in July of $\mathrm{O}_{3}, \mathrm{H}$, $\mathrm{OH}, \mathrm{HO}_{2}$ and $\mathrm{H}_{2} \mathrm{O}_{2}$ with an unperturbed water vapour profile (light dashed lines) and a water vapour profile modified by the freezedrying process (solid lines).

14:00 LT the water vapour mechanism is likely to dominate following sublimation of the particles as a result of the semidiurnal tide (von Zahn and Berger, 2003).

At $83 \mathrm{~km}$ a significant depletion of $\mathrm{O}_{3}$ is predicted. This is expected because of the fast photochemistry that links $\mathrm{O}$ and $\mathrm{O}_{3}$ (Brasseur and Solomon, 1984). The mesospheric $\mathrm{O}_{3}$ profile is currently best inferred from rocket-borne measurements of the $\mathrm{O}_{2}\left({ }^{1} \Delta\right)$ infrared emission, such as those described by Gumbel et al. (1998) which do in fact record a minimum in $\mathrm{O}_{3}$ at $83 \mathrm{~km}$. The modelled peak $\mathrm{O}_{3}$ concentration at about $88 \mathrm{~km}$ is enhanced by about a factor of two as a result of the dehydration of this region and the consequent reduction of odd hydrogen species. The peak $\mathrm{O}_{3}$ concentration of $2 \times 10^{8} \mathrm{~cm}^{-3}$ is in good agreement with the rocket measurements of Gumbel et al. (1998).

Significant enhancements in the concentrations of $\mathrm{OH}$, $\mathrm{HO}_{2}$ and, to a lesser extent, $\mathrm{H}$ are observed at $83 \mathrm{~km}$. This enhancement is due in part to the direct photolysis of the additional water vapour at this altitude as well as the influence of the reduced $\mathrm{O}$ on the partitioning of the $\mathrm{HO}_{\mathrm{x}}$ species (reduced $\mathrm{O}$ favours the formation of $\mathrm{OH}$ and $\mathrm{HO}_{2}$ over $\mathrm{H})$. The enhancements of $[\mathrm{OH}]$ and $\left[\mathrm{HO}_{2}\right]$ at $83 \mathrm{~km}$ are significant, but the predicted enhancement of $\mathrm{H}_{2} \mathrm{O}_{2}$ is dramatic since its rate of formation is dependent upon $[\mathrm{OH}]^{2}$ and $\left[\mathrm{HO}_{2}\right]^{2}$. Arnold and Krankowsky (1974) published results from several rocket-borne mass spectrometric measurements launched from Andøya in Northern Norway $\left(69^{\circ} \mathrm{N}\right)$ at different times of the year, where the $\mathrm{H}_{2} \mathrm{O}_{2}^{+}$ion was observed. The concentrations of $\mathrm{H}_{2} \mathrm{O}_{2}^{+}$, produced from $\mathrm{H}_{2} \mathrm{O}_{2}$ by charge transfer with $\mathrm{O}_{2}^{+}$, could be modelled satisfactorily in all but the summer measurements. They speculated that this discrepancy was due to much higher concentrations of $\mathrm{H}_{2} \mathrm{O}_{2}$ during summer. In later mass spectrometric measure- ments (Kopp et al., 1985b), positively charged clusters containing $\mathrm{H}_{2} \mathrm{O}_{2}$ were observed in the presence of NLC. Kopp et al. (1985b) concluded that the concentration of $\mathrm{H}_{2} \mathrm{O}_{2}$ must be higher than expected in order for these clusters to form. The redistribution of water vapour, and subsequently the odd hydrogen species, by the formation of ice particles is most likely the explanation for these enhanced $\mathrm{H}_{2} \mathrm{O}_{2}$ concentrations in the summer mesosphere.

\section{Conclusions}

The photochemical model described in this paper has been employed to investigate the potential impact of ice particles formation on the chemistry of the summer mesosphere. Attention has been focused on the atomic oxygen profile between 80 and $90 \mathrm{~km}$, the region in which these ice particles nucleate, grow and sediment, altering the water vapour profile as they do so. Three mechanisms have been suggested that may either directly or indirectly influence the atomic $\mathrm{O}$ profile: the uptake of atomic $\mathrm{O}$ on the ice particles; the modification of the water vapour profile by the freeze-drying effect and the subsequent impact on the odd hydrogen-oxygen interactions; and the direct photolysis of the large ice particles at the base of the aerosol layer, to form $\mathrm{H}$ and $\mathrm{OH}$.

Laboratory studies show that the uptake coefficient of $\mathrm{O}$ on ice at temperatures representative of the mesosphere is only $1 \times 10^{-5}$ (Murray and Plane, 2003b), a factor of at least $5 \times 10^{3}$ times too small to influence the odd oxygen chemistry of the summer mesosphere. In contrast, the enhancement of odd hydrogen, through the photolysis of water vapour or ice, may have a significant impact on the $\mathrm{O}$ profile when the cloud layer is irradiated by Lyman- $\alpha$ radiation at solar zenith angles less than $\approx 80^{\circ}$. The effect of enhanced water vapour at the base of the cloud can be modelled with reasonable confidence, whereas the photolysis of ice particles is uncertain because the efficiency with which $\mathrm{H}$ and $\mathrm{OH}$ are ejected into the gas phase is poorly known. In the modelling study presented here, this efficiency is assumed to be unity, whereas Westley et al. (1995) suggest that the primary desorption product from the Lyman- $\alpha$ irradiation of ice films is $\mathrm{H}_{2} \mathrm{O}$. However, they performed their experiments at below $100 \mathrm{~K}$, with ice films that were $500 \mathrm{~nm}$ thick. Release of $\mathrm{H}$ and $\mathrm{OH}$ from the ice matrix before they recombine to form $\mathrm{H}_{2} \mathrm{O}$ should be more efficient at higher temperatures and in thinner ice films, or by analogy small ice particles. Laboratory measurements of the $\mathrm{H}$ and $\mathrm{OH}$ yield from ice under conditions pertinent to the summer mesosphere are required to properly quantify the importance of the ice photolysis mechanism. Nevertheless, this modelling study shows that the efficiency of $\mathrm{H}$ and $\mathrm{OH}$ production must approach unity to have a significant impact on the $\mathrm{O}$ profile.

The layer of enhanced water vapour that results from the evaporation of ice particles will produce additional $\mathrm{H}$ and $\mathrm{OH}$ through photolysis, resulting in a depletion of O. Indeed, an 
enhancement factor of 4 , consistent with satellite measurements (Summers et al., 2001), should produce depletions of close to an order of magnitude. Von Zahn and Berger (2003) show that the sublimation of ice particles should only occur significantly around 02:00 and 14:00 LT. Hence, the largest $\mathrm{O}$ depletions resulting from this mechanism are expected at 14:00 LT, when $\chi$ is small. In the absence of a method for measuring the water vapour profile with high spatial resolution in the sunlit high latitude summer mesosphere (Khaplanov et al., 1996), simultaneous measurements of $\mathrm{O}$ and NLC appear to provide a means of testing for the presence of the water-vapour layer and the freeze-drying process predicted by microphysical models.

All rocket measurements of atomic $\mathrm{O}$ in the high latitude summer mesosphere have been made when $\chi>90^{\circ}$. Hence, these mechanisms involving the photolysis of water vapour or ice particles could not have been important at the time of these flights. The minimum in the $\mathrm{O}$ profile observed between 83 and $84 \mathrm{~km}$ appears to result from the very unusual photochemical environment that exists at high $\chi$, as opposed to an additional loss mechanism for $\mathrm{O}$. At high $\chi$ there is a dramatic reduction in $\mathrm{HO}_{\mathrm{x}}$ below $82 \mathrm{~km}$ and a ledge of very steep scale height forms between 82 and $83 \mathrm{~km}$. The result of this is that the $\mathrm{O}$ below about $84 \mathrm{~km}$ is very efficiently removed, which creates a very steep scale height on the $\mathrm{O}$ ledge and a minimum of $\mathrm{O}$ at about $83 \mathrm{~km}$. The minimum is reinforced by the severe attenuation of the main water photolysis wavelength, Lyman- $\alpha$, below $80 \mathrm{~km}$, which results in a maximum $\mathrm{HO}_{\mathrm{x}}$ production rate at around $85 \mathrm{~km}$. This has the result of causing the greatest removal of $\mathrm{O}$ just beneath the $\mathrm{O}$ ledge.

$\mathrm{Xu}$ et al. (2001) show that gravity wave destabilisation, which results in the waves breaking and depositing turbulence, is proportional to the $[\mathrm{O}]$ gradient, since reactions involving $\mathrm{O}$ produce a significant quantity of heat in the upper mesosphere and lower thermosphere. The modelling presented in this paper shows that the O ledge is steep without a freeze-drying effect, but with the freeze-drying effect the scale height decreases by a factor of 1.5 in the daytime. Hence, to what extent does the formation of mesospheric ice particles influence the breaking of gravity waves in the summer mesosphere and the deposition of turbulence? And to what extent might this feed back to the formation of mesospheric ice particles? Interestingly, Lübken (1997) shows that the majority of turbulence is deposited above the $\mathrm{O}$ ledge when NLC are present, but that this is not the case in winter when ice clouds are absent.

The formation of ice particles in the summer mesosphere impacts the concentrations of key species in the odd hydrogen and oxygen families. At the base of the aerosol layer where a water vapour layer forms, the model shows that enhancements in $\mathrm{OH}, \mathrm{HO}_{2}$ and $\mathrm{H}_{2} \mathrm{O}_{2}$ profiles as well as a depletion in the $\mathrm{O}_{3}$ profile can be expected. Rocket-borne mass spectrometers have provided some evidence for enhanced $\mathrm{H}_{2} \mathrm{O}_{2}$ densities in this region. Measurements of $\mathrm{O}_{3}$ and $\mathrm{OH}$ by rocket-borne or satellite instruments might validate the predictions of this model and the microphysical models that predict a dramatic freeze-drying process in the summer high latitude mesosphere.

Acknowledgements. The authors gratefully acknowledge P. Espy (British Antarctic Survey) for supplying the Mie code, and T. Vondrak (University of East Anglia) for his contribution in developing MESOMOD. We also acknowledge the financial support provided by the school of Environmental Sciences, University of East Anglia, for providing B. J. Murray with a Ph.D. studentship.

Edited by: W. Ward

\section{References}

Arnold, F. and Krankowski, D.: Measurements of hydrogen peroxide (1+) ion in the D-region and implications for mesospheric hydrogen peroxide, Geophys. Res. Lett., 1, 243-245, 1974.

Baumgarten, G., Fricke, K. H., and von Cossart, G. T.: Investigation of the shape of noctilucent cloud particles by polarization lidar technique, Geophys. Res. Lett., 29, art. no. 1630, doi:10.1029/2001GL013877, 2002.

Berger, U. and von Zahn, U.: Icy particles in the summer mesopause region: Three-dimensional modeling of their environment and two-dimensional modeling of their transport, J. Geophys. ResSpace Phys., 107, art. no. 1366, doi:10.1029/2001JA000316, 2002.

Brasseur, G. and Solomon, S.: Aeronomy of the Middle Atmosphere, D. Reidel Publishing Company, Dordrecht, 1984.

Chu, X. Z., Gardner, C. S., and Roble, R. G.: Lidar studies of interannual, seasonal, and diurnal variations of polar mesospheric clouds at the South Pole, J. Geophys. Res.-Atmos., 108, art. no. 8447, doi:10.1029/2002JD002524, 2003.

Dickinson, P. H. G., Bain, W. C., Thomas, E. R., Wiliams, D. B., Jenkins, D. B., and Twiddy, N. D.: The determination of the atomic oxygen concentration and associated parameters in the lower ionosphere, Proc. R. Soc. Lond. A., 369, 379-408, 1980.

Donahue, T.M., Guenther B., and Blamont J. E.: Noctilucent clouds in daytime: Circumpolar particulate layers near the summer mesopause, J. Atm. Sci, 29, 1205-1209, 1972.

Espy, P. J. and Jutt, H.: Equilibrium temperature of water-ice aerosols in the high- latitude summer mesosphere, J. Atmos. Terr. Phys., 64, 1823-1832, 2002.

Gadsden, M. and Schröder, W.: Noctilucent clouds, Springer Verlag, Berlin, 1989.

Garcia, R. R. and Solomon, S.: A New Numerical-Model of the Middle Atmosphere, 2. Ozone and Related Species, J. Geophys. Res.-Atmos., 99, 12 937-12 951, 1994.

Gumbel, J.: Rocket-Borne Optical Measurements of Minor Constituents in the Middle Atmosphere, PhD thesis, Stockholm University, Stockholm, 1997.

Gumbel, J., Murtagh, D. P., Espy, P. J., Witt, G., and Schmidlin, F. J.: Odd oxygen measurements during the Noctilucent Cloud 93 rocket campaign, J. Geophys. Res-Space Phys., 103, 23 399$23414,1998$.

Hedin, A. E.: Extention of the MSIS thermosphere model into the middle and lower atmosphere, J. Geophys. Res., 96, 1159-1172, 1991. 
Keyser, L. F. and Leu, M. T.: Morphology of nitric acid and water films, Microsc. Res. Tech., 25, 434-438, 1993.

Khaplanov, M., Gumbel, J., Wilhelm, N., and Wilt, G.: Hygrosonde - A direct measurement of water vapor in the stratosphere and mesosphere, Geophys. Res. Lett., 23, 1645-1648, 1996.

Khosravi, R., Brasseur, G., Smith, A., Rusch, D., Walters, S., Chabrillat, S., and Kockarts, G.: Response of the mesosphere to human-induced perturbations and solar variability calculated by a 2 -D model, J. Geophys. Res.-Atmos., 107, art. no. 4358, doi:10.1029/2001JD001235, 2002.

Kopp, E., Bertin, F., Bjorn, L. G., Dickinson, P. H. G., Philbrick, C. R., and Witt, G.: The 'CAMP' campaign 1982, Proceedings of the 7th ESA symposium on European rocket and balloon programmes and related research, 117-123, 1985a.

Kopp, E., Eberhardt, P., Herrmann, U., and Björn, L. G.: Positive Ion Composition in the High-Latitude Summer D Region with Noctilcucent Clouds, J. Geophys. Res.-Atmos., 90, 13 04113 053, 1985b.

Lübken, F. J., Rapp, M., and Hoffmann, P.: Neutral air turbulence and temperatures in the vicinity of polar mesosphere summer echoes, J. Geophys. Res.-Atmos., 107, art. no. 4273, doi:10.1029/2001JD000915, 2002.

Lübken, F. J.: Seasonal variation of turbulent energy dissipation rates at high latitudes as determined by in situ measurements of neutral density fluctuations, J. Geophys. Res.-Atmos., 102, 13 441-13 456, 1997.

Lübken, F. J.: Thermal structure of the Arctic summer mesosphere, J. Geophys. Res.-Atmos., 104, 9135-9149, 1999.

Murray, B. J.: The Uptake of Atomic Oxygen and Iron on Ice: Impact of Ice Particles on Mesospheric Chemistry, PhD thesis, University of East Anglia, Norwich, 2003.

Murray, B. J. and Plane, J. M. C.: Atomic oxygen depletion in the vicinity of noctilucent clouds, Adv. Space. Res., 31, 2075-2084, 2003a.

Murray, B. J. and Plane, J. M. C.: The uptake of atomic oxygen on ice films: Implications for noctilucent clouds, Phys. Chem. Chem. Phys., 5, 4129-4138, 2003 b.

Murtagh, D. P.: The O-2 Schumann-Runge System - New Calculations of Photodissociation Cross-Sections, Planet Space Sci., 36, 819-828, 1988.

Olivero, J.: Surface (Catalytic) reactions on Upper Atmospheric Aerosols, J. Geophys. Res., 79, 476-478, 1974.

Plane, J. M. C., Murray, B. J., Chu, X., and Gardener, C. S.: Removal of meteoric iron on polar mesospheric clouds, Science, 304, 426-428, 2004.
Ratkowski, A. J., Picard, R. H., Winick, J. R., Grossmann, K. U., Homann, D., Ulwick, J. C., and Paboojian, A. J.: LowerThermospheric Infrared Emissions from Minor Species During High-Latitude Twilight, B. Analysis of $15 \mathrm{Mu}-\mathrm{M}$ Emission and Comparison with Non-LTE Models, J. Atmos. Terr. Phys., 56, 1899-1914, 1994.

Sander, S. P., Kurylo, M. J., Orkin, V. L., Golden, D. M., Huie, R. E., Finlayson-Pitts, B. J., Kolb, C. E., Molina, M. J., Friedl, R. R., Ravishankara, A. R., and Moortgat, G. K.: Chemical Kinetics and Photochemical Data for Use in Atmospheric Studies: Evaluation 14, Jet Propulsion Laboratory, California, 2003.

Shimazaki, T.: Minor Constituents in the Middle Atmosphere, D. Reidel Publishing Company, Dordrecht, 1985.

Summers, M .E., Conway, R. R., Englert, C. R., Siskind, D. E., Stevens, M. H., Russell, J. M., Gordley, L. L., and McHugh, M. J.: Discovery of a water vapor layer in the Arctic summer mesosphere: Implications for polar mesospheric clouds, Geophys. Res. Lett., 28, 3601-3604, 2001.

Thomas, G. E.: Mesospheric clouds and the physics of the mesopause region, Rev. Geophys., 29, 553-575, 1991.

von Zahn, U. and Berger, U.: Persistent ice cloud in the midsummer upper mesosphere at high latitudes: Three-dimensional modeling and cloud interactions with ambient water vapor, J. Geophys. Res.-Atmos., 108, art. no. 8451, doi:10.1029/2002JD002409, 2003.

Warren, S.: Optical constants of ice from the ultraviolet to the microwave, Appl. Opt., 23, 1206-1225, 1984.

Watanabe, N., Horii, T., and Kouchi, A.: Measurements of D-2 yields from amorphous D2O ice by ultraviolet irradiation at $12 \mathrm{~K}$, Astrophys. J., 541, 772-778, 2000.

Westley, M. S., Baragiola, R. A., Johnson, R. E., and Baratta, G. A.: Ultraviolet Photodesorption from Water Ice, Planet Space Sci., 43, 1311-1315, 1995a.

Westley, M. S., Baragiola, R. A., Johnson, R. E., and Baratta, G. A.: Photodesorption from Low-Temperature Water Ice in Interstellar and Circumsolar Grains, Nature, 373, 405-407, 1995 b.

$\mathrm{Xu}$, J., Smith, A. K., and Brasseur, G. P.: Conditions for the photochemical destabilisation of gravity waves in the mesosphere, J. Atmos. Terr. Phys., 63, 1821-1829, 2001.

Yabushita, A., Hashikawa, Y., Ikeda, A., Kawasaki, M., and Tachikawa, H.: Hydrogen atom formation from the photodissociation of water ice at 193 nm, J. Chem. Phys., 119, 1-6, 2003.

Young, K. C.: Microphysical Processes in Clouds, Oxford University Press, New York, 1993. 